\title{
Coronary Artery Calcium Scores: Current Thinking and Clinical Applications
}

\author{
Anil George and Assad Movahed*
}

\begin{abstract}
Professor of Medicine and Radiology, Associate Division Chief, Director of Nuclear Cardiology, Cardiovascular Science Department, Director of Cardiovascular Imaging Center, The Brody School of Medicine, Pitt County Memorial Hospital, 600 Moye Boulevard, Greenville, NC 27834 USA
\end{abstract}

\begin{abstract}
Most incident coronary disease occurs in previously asymptomatic individuals who were considered to be at a lower risk by traditional screening methods. There is a definite advantage if these individuals could be reclassified into a higher risk category, thereby impacting disease outcomes favorably. Coronary artery calcium scores have been recognized as an independent marker for adverse prognosis in coronary disease. Multiple population based studies have acknowledged the shortcomings of risk prediction models such as the Framingham risk score or the Procam score. The science behind coronary calcium is discussed briefly followed by a review of current thinking on calcium scores. An attempt has been made to summarize the appropriate indications and use of calcium scores.
\end{abstract}

\section{INTRODUCTION}

The 2008 report from the American Heart Association Statistics Committee and Stroke Statistics Subcommittee includes some sobering projections on the outlook for Coronary Artery Disease in the current year. Approximately 770,000 Americans are expected to have a new myocardial infarction and about 430,000 will have a recurrent heart attack [1]. This amounts to an American experiencing a coronary event every 26 seconds and a resultant fatality every minute [1]. Diseases of the heart continue to rank as the leading killer for both sexes in this country and account for $27.2 \%$ of total deaths [2].

\section{RISK FACTORS FOR CORONARY ARTERY DIS- EASE}

In no other disease entity is the assessment of risk factors more important, than in CAD. This is due to cost implications and also due to the fact that events, sometimes fatal, can be averted. Risk stratification in CAD assumes greater importance also because it determines the type of tests that may be ordered by a clinician and also helps him or her choose between invasive and non-invasive treatment modalities [3].

The Framingham risk score was based on data from the Framingham Heart Study, one of the longest running prospective studies on CAD, and estimates 10-year coronary heart disease outcomes. It includes age, sex, total cholesterol, HDL cholesterol, smoking status, systolic blood pressure and use of anti-hypertensives [4]. It has long been acknowledged that these so called "traditional risk factors" are unable to account for all cases of CAD. It is also evident that the

\footnotetext{
*Address correspondence to this author at the Professor of Medicine and Radiology, Associate Division Chief, Director of Nuclear Cardiology, Cardiovascular Sciences Department, Director of Cardiovascular Imaging Center, The Brody School of Medicine, Pitt County Memorial Hospital, 600 Moye Boulevard, Greenville, NC 27834 USA; Tel: 252-744-4651, 252-7440774; Fax: 252-744-5884;

E-mails: movaheda@ecu.edu, anilgeorge@gmail.com
}

findings from the Framingham cohort cannot be generalized to the rest of the population or other ethnic groups, as that was a study done on an almost entirely Caucasian population. There is also a concern that the model routinely underestimates coronary risk in women and African Americans of either sex [5]. This has spurred interest in the quest for novel cardiovascular risk factors. Examples include, CRP, Lipoprotein-A, Homocysteine, abdominal obesity, coronary artery calcium, carotid intima media thickness, lack of physical activity and psychosocial stress to name just a few.

This review tries to synthesize the current literature on coronary artery calcium and its detection by CT as a tool for risk assessment. We have also touched upon novel imaging techniques that incorporate functional and anatomic data in newer hybrid techniques that help in clinical decision making.

\section{THE ROLE OF CALCIUM IN THE ATHEROSCLE- ROTIC PLAQUE}

It will be useful to recapitulate the evolution of the atherosclerotic plaque and the role of calcium at a microscopic and macroscopic level in it. Endothelial cells, leukocytes and intimal smooth muscle cells are the main cellular agents responsible for atherosclerosis. Exposure of vascular endothelium to atherogenic stimuli results in extra cellular lipid accumulation which leads to recruitment of leukocytes. The major leukocytes involved in this process are monocytes and T-Lymphocytes. The monocytes subsequently imbibe lipid and evolve into the "foam cell" or lipid laden macrophage which is considered the pathological hallmark of the atherosclerotic plaque. CAC occurs, and increases with age and develops in advanced atherosclerotic plaques although it is worth noting that absence of calcification does not imply absence of atherosclerosis [6]. The non-calcified atherosclerotic lesions (NCALs) or "soft plaques" occupy a very prominent role in CAD as they are thought to be more unstable and therefore more "vulnerable". However, CAC is not specific for luminal obstruction as there are other factors that come into play including vascular remodeling which impact 
arterial lumen and coronary blood flow. Arterial lumen was studied in humans and nonhuman primates by Clarkson, et $a l$. who concluded that lack of remodeling may be a major factor in certain individuals with coronary atherosclerosis not developing complications such as myocardial infarction [7].

Atherosclerotic calcification mainly involves the intimal layer of the artery as opposed to the more classical medial calcification (Monckeberg's medial calcinosis), which is common in diabetic patients [8]. Numerous bone proteins are found in the atherosclerotic plaque and Osteopontin, a protein involved in mineralization has been specifically associated with calcific coronary atheroma and is thought to play an important role in the onset and progression of disease in humans [9]. Smooth muscle cells are thought to secrete cytokines that facilitate calcium formation in the atheroma. In vitro studies have been performed, in which the ionic concentrations of calcium and phosphorous were simulated to mimic serum concentrations, and the resulting carbonate bioapatite precipitates were found to resemble closely, the calcified atherosclerotic plaques seen in human blood vessels [10].

\section{CALCIUM SCORES}

The amount of calcium in the coronary arteries can be quantitated. Various methods have been proposed for this purpose. The most attractive and the most commonly used is the Agatston score. Other methods described include calcium volume and mass (mineral) scores.

\section{AGATSTON SCORES}

Agatston, et al. described a novel way of measuring coronary artery calcium in 1990 [11]. They used ultra fast CT to measure total calcium scores based on the number, areas and peak Hounsfield computed tomographic numbers of the calcific lesions detected. Subsequent studies have confirmed the high correlation between calcium scores and histopathologic coronary disease and also that absence of calcification was highly indicative of absence of CAD [12, 13]. Inter reader variability of the Agatston score is about $3 \%$, intra reader variability is less than $1 \%$ and inter scan variability is thought to be about $15 \%$ [11].

\section{VOLUME SCORE}

The calcium volume can be calculated by multiplying the number of voxels $\left(\mathrm{V}_{\mathrm{n}}\right)$ with the voxel volume $\left(\mathrm{V}_{\mathrm{v}}\right)$ using a technique of isotropic interpolation as mentioned by Callister et al. [14]. The main limitations of this technique, are that a third spatial dimension of the plaque is not taken into account, and that, there is introduction of an arbitrary attenuation scaling factor [14].

\section{MASS SCORE}

The mass score is calculated as the product of the calcium concentration and calcified plaque volume [15].

\section{CALCIUM SCORE IN PREDICTING THE RISK OF CARDIAC EVENTS}

Coronary calcium does predict risk since, in some measure it quantifies the total atherosclerotic burden [16]. A majority of acute cardiovascular events, i.e., strokes and myo- cardial infarctions occur in subjects who are not considered to be at high risk for these events by traditional screening techniques in vogue, for e.g., the Framingham Risk Score or Procam score. Furthermore, calcification is known to be intimately associated with atherosclerosis even from a preatheroma stage and is known to increase with age [17, 18]. Large observational cohorts studied to date, with zero calcium scores are known to have a low adverse cardiac event risk [19]. A large observational cohort of over 25,000 asymptomatic subjects was followed in a study by Budoff $e t$ $a l$. in which coronary artery calcification (CAC) was found to be an independent predictor for all cause mortality [20].

There is a wealth of data which supports the use of CAC as a surrogate for coronary atherosclerosis confirmed by correlation of angiographic, histopathologic and necropsy studies [21, 22]. It was shown by Mautner et al. that the amount of calcium deposits measured by EBCT correlates very well with histomorphometric measurements [23]. A study by Rumberger et al. demonstrated that increasing amounts of coronary artery calcium by $\mathrm{CT}$ were found to correlate with more advanced atherosclerotic involvement of the coronaries detected by histological section [24].

\section{CALCIUM SCORE IN COMPARISON TO TRADI- TIONAL RISK FACTORS}

The importance of a risk assessment tool to transcend racial and ethnic barriers cannot be over emphasized given the rapidly shifting demographic patterns in the United States and the rest of the world. The FRS was developed originally in an almost exclusively Caucasian population which results in erroneous risk estimations when applied to a broader population which includes other ethnic groups. Clinicians may be disinclined to incorporate risk prediction models and treatment guidelines derived from them if the risk prediction functions do not have good portability outside the settings where they were originally conceived [25]. Investigators have circumvented this problem by either recalibrating these tools or combining with them additional tests such as CAC [26].

More recently, data from the Multi-Ethnic Study of Atherosclerosis (MESA) cohort which had multi racial representation was used to demonstrate that CAC is a strong predictor of incident coronary disease and provided predictive information beyond that was provided by traditional risk factors [27]. This was demonstrated in all the major racial groups studied and is therefore a major advantage of CAC over the FRS.

\section{CLINICAL APPLICATIONS OF CALCIUM SCORING}

The value of any clinical test depends on its ability to primarily, diagnose a condition and secondarily, to help impart changes that alter the natural history of the disease and thereby improve outcomes. Coronary artery calcium has the unique status of being a risk factor for CAD and at the same time can be imaged by CT.

Schenker, et al. have shown that evaluation of atherosclerotic disease burden anatomically by CAC scores, provides incremental prognostic information when coupled with physiologic data from myocardial perfusion imaging [28]. Another application is use of Cardiac CT as a gatekeeper to myocardial perfusion PET study in patients with chest pain 
evaluated in a setting such as the emergency room. In this context, absence of CAC would be predictive of a normal PET study and could thus be potentially avoided. This has been demonstrated by Esteves, et al. who found that such an approach would be cost effective, minimize radiation exposure and likely decrease length of stay in the hospital [29]. The pairing of complementary imaging technologies such as CT and PET, which provide anatomic and physiologic data respectively, has spawned Hybrid PET-CT techniques for the detection of CAD. Sampson et al. have reported the use of rubidium-82 myocardial perfusion PET-CT with sensitivity up to $93 \%$ and specificity of $83 \%$ for the detection of obstructive CAD [30].

In the Multi-Ethnic Study of Atherosclerosis (MESA) study, Wang et al. studied a patient population that did not carry a diagnosis of CAD. The parameters that were measured in this study included myocardial blood flow measured using MRI, during rest and adenosine induced hyperemia and Agatston scores for coronary calcification measured by multi-detector CT. The study showed that independent of the presence of risk factors for CAD, myocardial perfusion reserve was inversely correlated with the presence and severity of CAC in asymptomatic adults [31]. In the PACC (Prospective Army Coronary Calcium) project Taylor, et al. in a study of 2000 subjects found that coronary calcium provides substantial, independent prognostic information in predicting new onset CAD [32]. The status of the calcium score as an independent predictor for coronary events has been established based on meta analyses of various studies by Pletcher, et al. (Table 1) [33].

Table 1. Adjusted Odds Ratios (OR) Comparing Risk of A Coronary Heart Disease Event in Persons with Low (1-100), Medium (101-400), and High (>400) Coronary Artery Calcium (CAC) Scores to Persons Without Calcification. 95\% Confidence Intervals are Given in Parenthesis $(\mathbf{P}<.001)^{\mathrm{a}}$

\begin{tabular}{|c|c|}
\hline CAC Score & Adjusted Odds Ratio \\
\hline \hline $1-100$ & $2.1(1.6-2.9)$ \\
\hline $101-400$ & $5.4(2.2-13)$ \\
\hline$>400$ & $10(3.1-34)$ \\
\hline
\end{tabular}

${ }^{a}$ Ref. [33].

Results from the Rotterdam Coronary Calcification study which involved over 2000 elderly subjects demonstrated that, risk prediction based on cardiovascular risk factors improved when coronary calcification was added to the model [34]. CAC measured by CT can identify a high risk group with silent myocardial ischemia who can than be selected for further intensive therapeutic options and, or, invasive angiography after SPECT [35]. Moser et al. have established an Agatston score of 400 as a threshold number for initiating myocardial SPECT testing; also an Agatston score less than 100 is very unlikely to be associated with an abnormal SPECT study [36]. In the same context it has been noted that an Agatston score greater than 400 in patients who are receiving appropriate medical therapy for CAD is associated with ischemia implying that these patients may need to be managed differently [37]. In another more recent study by Ho, et al. it was found that, as CAC scores increased, there was an increase in the frequency of MDCT detected obstructive stenosis, a relation which was maintained after adjustment for traditional risk factors [38]. A similar conclusion was arrived at by a prospective study of over 10,000 subjects conducted by Church, et al. who conclude that CAC can identify individuals at increased risk of CAD death or nonfatal MI who would otherwise be considered low risk [39].

In a study of over 1700 asymptomatic subjects Becker, et al. demonstrated that by the determination of CAC, patients at a higher risk for CAD could be identified. In this study the Agatston score was compared with the ATP III risk score and the Procam score and was shown to have a higher diagnostic accuracy for CAD [40]. A smaller study by Achenbach, et al. compared CAC measured by EBCT with predicted 10-year cardiovascular risk determined by FRS, ATP III and Procam and found that there was very low correlation between the two [41]. These studies which pitch CAC against traditional risk stratification models, highlight the disconnect between the various models and have brought $\mathrm{CAC}$ and other modalities to the forefront in the quest for newer, more reliable risk evaluation strategies.

The progression of CAC on serial EBCT was found to be greater in patients with future myocardial infarctions raising the possibility that patient subsets can be sampled out for follow up on serial exams especially for delineating response to therapy and improving risk profiles [42]. Even when used with dual source $64 \mathrm{CT}$, the combined use of CAC scores and CTA was found to improve the specificity of assessing coronary stenoses from $87 \%$ to $100 \%$ without decreasing sensitivity [43]. CAC can be used to distinguish ischemic from non-ischemic cardiomyopathy with the presence of calcium signifying ischemia as a potential etiology [44, 45]. Given the shortcomings of traditional risk factors in predicating cardiovascular events and the strength of CAC as an independent predictor for coronary events, new methods of risk prediction which incorporate both $\mathrm{CAC}$ and traditional risk factors have been introduced [46].

\section{LIMITATIONS}

The calcium score may not give accurate risk estimates in special patient populations such as uremic subjects and should not be used as a test in isolation in the risk stratification of these patients [47]. Another obvious disadvantage is the use of CT and concomitant radiation exposure. The magnitude of radiation exposure depends among other factors on EKG pulsing and certain studies have quoted radiation doses up to $21.4 \mathrm{mSv}$ without the use of EKG pulsing compared to a mean of $5.6 \mathrm{mSv}$ for diagnostic catheter angiographies [48]. Hausleiter, et al. report that the average radiation dose estimates ranged from a mean of $6.4 \pm 1.9$ and $11.0 \pm 4.1 \mathrm{mSv}$ for 16- and 64-slice CT, respectively. They further note, that decrease in radiation exposure can be achieved by EKGdependent dose modulation, reduced tube voltage and most importantly better patient selection [49]. Ongoing advances in CT technology could in the near future decrease the amount of radiation dose considerably. It must be mentioned that cost is another factor which makes CAC less appealing as a screening test. 
Table 2. Cost Effectiveness of Alternative Strategies for Cardiovascular Prevention (in \$1000) ${ }^{\mathrm{b}}$

\begin{tabular}{|c|c|c|c|}
\hline Measure & Shape vs. NCEP & Treat All vs. NCEP & Treat All vs. Shape \\
\hline \hline Gross cost per life saved & $\$ 1467$ & $\$ 1346$ & $\$ 1167$ \\
\hline Gross cost per life-year saved & $\$ 113$ & $\$ 104$ & $\$ 90$ \\
\hline Gross cost per LYE saved & $\$ 49$ & $\$ 45$ & $\$ 39$ \\
\hline Net cost per LYE saved & $\$ 32$ & $\$ 28$ & $\$ 22$ \\
\hline
\end{tabular}

$\{$ LYE=Life year; SHAPE= Screening for Heart Attack Prevention and Education;

NCEP $=$ National Cholesterol Education Program $\}$

${ }^{\mathrm{b}}$ Ref. [52]

\section{CONCLUSION}

Calcium scores appear to be a new and formidable component of the armamentarium at the clinicians' disposal, one we think has already started to impact the practice of cardiovascular medicine favorably. Taylor, et al. mention an independent three fold greater likelihood of use of statins and aspirin in a follow up study on their PACC project cohort which used CAC [50]. Combining calcium scores with other techniques such as MPS, results in better patient selection for invasive and potentially more expensive treatment options, which translates into better outcomes and more health care dollars saved.

The quest for new clinical tools to better risk stratify patients, particularly the elderly is gaining momentum. Furthermore, in the elderly, especially over the age of 50 years, the association of risk factors like cholesterol, with mortality is confounded by the presence of comorbidities [51]. However more clinical studies may have to be done before calcium scores and Cardiac CT are able to find a better defined role in the diagnostic algorithms for coronary disease. The ACCF/AHA consensus statement on the subject considers the use of CAC scores favorably, especially in intermediate risk patient populations based on the possibility that they may be reclassified into a higher risk status based on calcium scores, a decision that could impact their subsequent treatment plans and also clinical outcome [52]. The adoption of nascent technology is turbulent in all disciplines and cardiovascular medicine is no exception. There is a raging controversy over the suggested use of CT or Ultrasound in asymptomatic individuals (the SHAPE taskforce recommendations) with the aim to institute pharmacological prevention, an issue that raises scientific and financial controversy. The ramifications arising from the above, especially the economic implications, are dissected by Diamond, et al. (Table 2) in great detail $[53,54]$.

A full discussion of the SHAPE task force recommendations, and the controversies arising there from, is beyond the scope of this review. Dr. Harvey Hecht laments on the subject in his well written take on the matter, that (it) is "incumbent on the cardiology community to temper the inflexible need for randomized trials with the reality of 565,000 patients presenting with myocardial infarctions annually as their first symptoms, $95 \%$ of whom could be identified as at high risk by CAC screening and aggressively treated to significantly reduce events" [55]. It may be prudent at this point to summarize the appropriateness criteria for CAC as advocated by the ACCF/AHA consensus document (Table 3) [52].

Table 3. Appropriateness Criteria for Calcium Score Estimation as Recommended by ACCF/AHA

\begin{tabular}{|c|c|c|}
\hline Clinical Scenario & Recommendations & Comment \\
\hline $\begin{array}{l}\text { Asymptomatic patients with interme- } \\
\text { diate CHD risk(10-20\% } 10 \text { year risk) }\end{array}$ & May be reasonable to use CAC. & $\begin{array}{l}\text { These patients may be reclassified to a higher risk status } \\
\text { based on CAC and management may be modified. }\end{array}$ \\
\hline $\begin{array}{c}\text { Patients with low CHD risk }(<10 \% 10 \\
\text { year risk) }\end{array}$ & Does not recommend use of CAC. & Such use is similar to population screening scenario. \\
\hline $\begin{array}{c}\text { Asymptomatic patients with }>20 \% 10 \\
\text { year CHD risk }\end{array}$ & Does not recommend use of CAC. & $\begin{array}{c}\text { These patients are already candidates for intensive risk } \\
\text { reduction. }\end{array}$ \\
\hline $\begin{array}{l}\text { Patients with } \mathrm{CAC}=0 \text { who are other- } \\
\text { wise intermediate risk }\end{array}$ & No evidence available for consensus judgment. & $\begin{array}{l}\text { Recommendations for intermediate risk patients should } \\
\text { apply. }\end{array}$ \\
\hline $\begin{array}{l}\text { Patients with intermediate risk and } \\
\text { choice of alternate tests }\end{array}$ & $\begin{array}{c}\text { CAC has not been compared head to head with } \\
\text { other tests. }\end{array}$ & Cannot be answered based on current evidence. \\
\hline High CAC & $\begin{array}{c}\text { Additional non-invasive testing is not recom- } \\
\text { mended. }\end{array}$ & $\begin{array}{l}\text { High risk patients with multiple risk factors or Diabetes } \\
\text { should get intensive therapy. }\end{array}$ \\
\hline Patients with atypical symptoms & $\begin{array}{l}\text { Low risk patients with atypical symptoms may } \\
\text { benefit from CAC testing. }\end{array}$ & $\begin{array}{l}\text { Other competing tests are also available with no head to } \\
\text { head comparisons done. }\end{array}$ \\
\hline Specific population groups & $\begin{array}{c}\text { Available data are strongest for Caucasian, non- } \\
\text { Hispanic men. }\end{array}$ & $\begin{array}{l}\text { Caution should be exercised in extrapolation of data to } \\
\text { women, African American men. }\end{array}$ \\
\hline Incidental findings on CAC & Appropriate follow up per radiology guidelines. & For example guidelines for small pulmonary nodules. \\
\hline
\end{tabular}


Although calcium score estimation is quite promising as a risk estimator, it is worth noting, that the premise does not exist at least currently, to endorse population based screening for coronary calcium. The place of CAC in the risk management algorithms for cardiovascular diseases is unsettled at this time, but promises to be a vexing question, given the shortcomings engendered by traditional risk scores.

\section{ABBREVIATIONS}

$\begin{array}{lll}\mathrm{CAD} & = & \text { Coronary Artery Disease } \\ \mathrm{CT} & = & \text { Computed Tomography } \\ \mathrm{CAC} & = & \text { Coronary Artery Calcium } \\ \text { FRS } & = & \text { Framingham Risk Score } \\ \text { EBCT } & = & \text { Electron Beam Computed Tomography } \\ \text { PET } & = & \text { Positron Emission Tomography } \\ \text { MRI } & = & \text { Magnetic Resonance Imaging } \\ \text { MPS } & = & \text { Myocardial Perfusion Scintigraphy }\end{array}$

\section{REFERENCES}

[1] Rosamond W, Flegal K, Furie K. Heart Disease and Stroke Statistics--2008 Update: A Report From the American Heart Association Statistics Committee and Stroke Statistics Subcommittee. Circulation 2008; 117: 25-146.

[2] Robert N. Anderson PD, Betty L. Smith BS Ed, Deaths: Leading Causes for 2002. 2007 03/07/2005 [cited 53 04/03/2008]; Available from: http: //www.cdc.gov/nchs/data/nvsr/nvsr53/nvsr53_17.pdf

[3] Litchfield RL. Noninvasive tests for cardiac risk stratification. Which ones are most prognostic?. Postgrad Med 2004; 115: 30-6.

[4] Wilson PWF, D'Agostino RB, Levy D, Belanger AM, Silbershatz $\mathrm{H}$, Kannel WB. Prediction of coronary heart disease using risk factor categories. Circulation 1998; 97: 1837-47.

[5] Michos ED, Nasir K, Braunstein JB, et al. Framingham risk equation underestimates subclinical atherosclerosis risk in asymptomatic women. Atherosclerosis 2006; 184: 201-6.

[6] Vashist A, Bonow RO. Screening for coronary atherosclerosis with coronary calcium scoring: The "shape" of things to come? J Nucl Cardiol 2008; 15: 162-9.

[7] Clarkson TB, Prichard RW, Morgan TM, Petrick GS, Klein KP. Remodeling of coronary arteries in human and nonhuman primates. JAMA 1994; 271: 289-94.

[8] Demer LL. Vascular calcification and osteoporosis: inflammatory responses to oxidized lipids. Int J Epidemiol 2002; 31: 737-41.

[9] Fitzpatrick LA, Severson A, Edwards WD, Ingram RT. Diffuse calcification in human coronary arteries. Association of osteopontin with atherosclerosis. J Clin Invest 1994; 94: 1597-604.

[10] Olsson, L.-F, Sandin K, Odselius R, Kloo L. In vitro formation of nanocrystalline carbonate apatite - a structural and morphological analogue of atherosclerotic plaques. Eur J Inorg Chem 2007; 41237 .

[11] Agatston AS, Janowitz WR, Hildner FJ, Zusmer NR, Viamonte M, Jr., Detrano R. Quantification of coronary artery calcium using ultrafast computed tomography. J Am Coll Cardiol 1990; 15: 827-32.

[12] Simons DB, Schwartz RS, Edwards WD, Sheedy PF, Breen JF, Rumberger JA. Noninvasive definition of anatomic coronary artery disease by ultrafast computed tomographic scanning: a quantitative pathologic comparison study. J Am Coll Cardiol 1992; 20: 111826.

[13] Rumberger JA, Simons DB, Fitzpatrick LA, Sheedy PF, Schwartz RS. Coronary artery calcium area by electron-beam computed tomography and coronary atherosclerotic plaque area : a histopathologic correlative study. Circulation 1995; 92: 2157-62.

[14] Callister TQ, Cooil B, Raya SP, Lippolis NJ, Russo DJ, Raggi P. Coronary artery disease: improved reproducibility of calcium scoring with an electron-beam CT volumetric method. Radiology 1998; 208: 807-14.

[15] Moselewski F, O'Donnell CJ, Achenbach S. Calcium concentration of individual coronary calcified plaques as measured by multidetector row computed tomography. Circulation 2005; 111: 3236-41.
[16] Weintraub WS, Diamond GA. Predicting cardiovascular events with coronary calcium scoring. N Engl J Med 2008; 358: 1394-6.

[17] Roijers RB, Dutta RK, Cleutjens JP, Mutsaers PH, de Goeij JJ, van der Vusse GJ. Early calcifications in human coronary arteries as determined with a proton microprobe. Anal Chem 2008; 80: 55-61.

[18] Hoffmann U, Brady TJ, Muller J. Cardiology patient page. Use of new imaging techniques to screen for coronary artery disease. Circulation 2003; 108: e50-3.

[19] Shareghi S, Ahmadi N, Young E, Gopal A, Liu ST, Budoff MJ. Prognostic significance of zero coronary calcium scores on cardiac computed tomography. J Cardiovasc Comput Tomogr 2007; 1: 155-9.

[20] Budoff MJ, Shaw LJ, Liu ST, et al. Long-term prognosis associated with coronary calcification: observations from a registry of 25,253 patients. J Am Coll Cardiol 2007; 49: 1860-70.

[21] Rifkin RD, Parisi AF, Folland E. Coronary calcification in the diagnosis of coronary artery disease. Am J Cardiol 1979; 44: 141-7. Rumberger JA, Sheedy PF 3rd, Breen JF, Schwartz RS. Coronary calcium, as determined by electron beam computed tomography, and coronary disease on arteriogram : effect of patient's sex on diagnosis. Circulation 1995; 91: 1363-7.

[23] Mautner GC, Mautner SL, Froehlich J, et al. Coronary artery calcification: assessment with electron beam CT and histomorphometric correlation. Radiology 1994; 192: 619-23.

[24] Rumberger JA, Schwartz RS, Simons DB, Sheedy PF 3rd, Edwards WD, Fitzpatrick LA. Relation of coronary calcium determined by electron beam computed tomography and lumen narrowing determined by autopsy. Am J Cardiol 1994; 73: 1169-73.

[25] D'Agostino SRB, Grundy S, Sullivan LM, Wilson P. CHDRPG. Validation of the framingham coronary heart disease prediction scores: results of a multiple ethnic groups investigation. JAMA 2001; 286: 180-7.

[26] Greenland P, LaBree L, Azen SP, Doherty TM, Detrano RC. Coronary artery calcium score combined with framingham score for risk prediction in asymptomatic individuals. JAMA 2004; 291: 210-5.

[27] Detrano R, Guerci AD, Carr JJ, et al. Coronary calcium as a predictor of coronary events in four racial or ethnic groups. N Engl J Med 2008; 358: 1336-45.

[28] Schenker MP, Dorbala S, Hong EC, et al. Interrelation of coronary calcification, myocardial ischemia, and outcomes in patients with intermediate likelihood of coronary artery disease: a combined positron emission tomography/computed tomography study. Circulation 2008; 117: 1693-700.

[29] Esteves FP, Sanyal R, Santana CA, Shaw L, Raggi P. Potential impact of noncontrast computed tomography as gatekeeper for myocardial perfusion positron emission tomography in patients admitted to the chest pain unit. Am J Cardiol 2008; 101: 149-52.

[30] Sampson UK, Dorbala S, Limaye A, Kwong R, Di Carli MF. Diagnostic accuracy of rubidium-82 myocardial perfusion imaging with hybrid positron emission tomography/computed tomography in the detection of coronary artery disease. J Am Coll Cardiol 2007; 49: 1052-8.

[31] Wang L, Jerosch-Herold M, Jacobs JDR, Shahar E, Detrano R, Folsom AR. Coronary artery calcification and myocardial perfusion in asymptomatic adults: the mesa (multi-ethnic study of atherosclerosis). J Am Coll Cardiol 2006; 48: 1018-26.

[32] Taylor AJ, Bindeman J, Feuerstein I, Cao F, Brazaitis M, O'Malley PG. Coronary calcium independently predicts incident premature coronary heart disease over measured cardiovascular risk factors: mean three-year outcomes in the Prospective Army Coronary Calcium (PACC) project. J Am Coll Cardiol 2005; 46: 807-14.

[33] Pletcher MJ, Tice JA, Pignone M, Browner WS. Using the coronary artery calcium score to predict coronary heart disease events: a systematic review and meta-analysis. Arch Intern Med 2004; 164 : 1285-92.

[34] Vliegenthart R, Oudkerk M, Hofman A, et al.Coronary calcification improves cardiovascular risk prediction in the elderly. Circulation $2005 ; 112$ : 572-7.

[35] He ZX, Hedrick TD, Pratt CM, et al. Severity of coronary artery calcification by electron beam computed tomography predicts silent myocardial ischemia. Circulation 2000; 101: 244-51.

[36] Moser KW, O'Keefe JH Jr, Bateman TM, McGhie IA. Coronary calcium screening in asymptomatic patients as a guide to risk factor modification and stress myocardial perfusion imaging. J Nucl Cardiol 2003; 10: 590-8. 
[37] Ho J, FitzGerald S, Stolfus L, Cannaday J, Radford N. Severe coronary artery calcifications are associated with ischemia in patients undergoing medical therapy. J Nucl Cardiol 2007; 14: 341-6.

[38] Ho JS, FitzGerald SJ, Stolfus LL, et al. Relation of a coronary artery calcium score higher than 400 to coronary stenoses detected using multidetector computed tomography and to traditional cardiovascular risk factors. Am J Cardiol 2008; 101: 1444-7.

[39] Church TS, Levine BD, McGuire DK, et al. Coronary artery calcium score, risk factors, and incident coronary heart disease events. Atherosclerosis 2007; 190: 224-31.

[40] Becker A, Leber A, Becker C, Knez A. Predictive value of coronary calcifications for future cardiac events in asymptomatic individuals. Am Heart J 2008; 155: 154-60.

[41] Achenbach S, Nomayo A, Couturier G, et al. Relation between coronary calcium and 10-year risk scores in primary prevention patients. Am J Cardiol 2003; 92: 1471-5.

[42] Raggi P, Cooil B, Shaw LJ, et al. Progression of coronary calcium on serial electron beam tomographic scanning is greater in patients with future myocardial infarction. Am J Cardiol 2003; 92: 827-9.

[43] Leschka S, Scheffel H, Desbiolles L, et al. Combining dual-source computed tomography coronary angiography and calcium scoring: added value for the assessment of coronary artery disease. Heart 2007; 94 (9): 11541-16.

[44] Shemesh J, Tenenbaum A, Fisman EZ, et al. Coronary calcium as a reliable tool for differentiating ischemic from nonischemic cardiomyopathy. Am J Cardiol 1996; 77: 191-4.

[45] Budoff MJ, Shavelle DM, Lamont DH, et al .Usefulness of electron beam computed tomography scanning for distinguishing ischemic from nonischemic cardiomyopathy. J Am Coll Cardiol 1998; 32: 1173-8.

[46] Pletcher MJ, Tice JA, Pignone M, McCulloch C, Callister TQ, Browner WS. What does my patient's coronary artery calcium score mean? Combining information from the coronary artery calcium score with information from conventional risk factors to estimate coronary heart disease risk. BMC Med 2004; 2: 31.
[47] Sharples EJ, Pereira D, Summers S, et al. Coronary artery calcification measured with electron-beam computerized tomography correlates poorly with coronary artery angiography in dialysis patients. Am J Kidney Dis 2004; 43: 313-9.

[48] Coles DR, Smail MA, Negus IS, et al. Comparison of radiation doses from multislice computed tomography coronary angiography and conventional diagnostic angiography. J Am Coll Cardiol 2006; 47: $1840-5$.

[49] Hausleiter J, Meyer T, Hadamitzky M, et al. Radiation dose estimates from cardiac multislice computed tomography in daily practice: impact of different scanning protocols on effective dose estimates. Circulation 2006; 113: 1305-10.

[50] Taylor AJ, Bindeman J, Feuerstein I, et al. Community-based provision of statin and aspirin after the detection of coronary artery calcium within a community-based screening cohort. J Am Coll Cardiol 2008; 51: 1337-41.

[51] Anderson KM, Castelli WP, Levy D. Cholesterol and mortality. 30 years of follow-up from the Framingham study. JAMA 1987; 257: 2176-80

[52] Greenland P, Bonow RO, Brundage BH, et al. ACCF/AHA 2007 clinical expert consensus document on coronary artery calcium scoring by computed tomography in global cardiovascular risk assessment and in evaluation of patients with chest pain: a report of the american college of cardiology foundation clinical expert consensus task force (accf/aha writing committee to update the 2000 expert consensus document on electron beam computed tomography) developed in collaboration with the society of atherosclerosis imaging and prevention and the society of cardiovascular computed tomography. J Am Coll Cardiol 2007; 49: 378-402.

[53] Naghavi M. Preventive cardiology: the shape of the future. Herz 2007; 32: 356-61.

[54] Diamond GA, Kaul S. The things to come of shape: cost and effectiveness of cardiovascular prevention. Am J Cardiol 2007; 99: 1013-5.

[55] Hecht HS. The deadly double standard (the saga of screening for subclinical atherosclerosis). Am J Cardiol 2008; 101 (12): 1805-7.

(c) George and Movahed; Licensee Bentham Open.

This is an open access article licensed under the terms of the Creative Commons Attribution Non-Commercial License (http: //creativecommons.org/licenses/by$\mathrm{nc} / 3.0 /$ ) which permits unrestricted, non-commercial use, distribution and reproduction in any medium, provided the work is properly cited. 